\title{
Argumentação acadêmica: análise da retórica do Guia prático para redação científica
}

\section{Gustavo Cândido Pinheiro}

Docente da Universidade da Integração Internacional da Lusofonia Afro-Brasileira (UNILAB), Brasil orcid.org/0000-0002-9620-7094

\author{
Júlio César Araújo
}

Docente da Universidade Federal do Ceará (UFC), Brasil orcid.org/0000-0001-7399-3769

Realizamos aqui uma interpretação de algumas orientações para escrita presentes no Guia prático para redação científica (VOLPATO, 2015). Um manual, segundo seu autor, destinado a auxiliar pesquisadores a redigir artigos acadêmicos em um padrão internacional. Nossos objetivos são analisar: (1) as estratégias retóricas na produção de conhecimento sobre escrita científica e (2) os posicionamentos sobre redação científica (implicado nisso, sobre ciência de maneira geral) presentes em tais orientações. Como referencial teórico-metodológico, estabelecemos um diálogo entre perspectivas de estudos que concebem a linguagem como uma ação e, nesse sentido, dão ênfase à dimensão retórica e performativa da ação humana, sobretudo a ação da escrita acadêmica (BAZERMAN, 2015; 2011; 2005; FIORIN, 2015; RAJAGOPALAN, 2014; 2008; 1998; HYLAND, 2011; 2000). Como resultados, a presente pesquisa oferece subsídios para uma melhor compreensão a respeito de visões dominantes sobre escrita científica e sobre a necessidade do respeito à diversidade de culturas disciplinares (HYLAND, 2011).

Palavras-chave: Redação científica. Retórica. Performatividade. Culturas disciplinares.

\section{Argumentación académica: análisis de la retórica de la Guía práctica para redacción científica}

Realizamos una interpretación de algunas orientaciones para escritura presentes en la Guía práctica para redacción científica (VOLPATO, 2015). Un manual, según su autor, destinado a ayudar a los investigadores a redactar artículos académicos siguiendo patrones internacionales. Nuestros objetivos son analizar: (1) las estrategias retóricas en la producción de conocimiento sobre escritura científica y (2) las posiciones sobre redacción científica (implicado, sobre ciencia en general) presentes en estas orientaciones. Como marco teórico-metodológico, establecemos un diálogo entre perspectivas de estudios que conciben el lenguaje como una acción y, en este sentido, enfatizan la dimensión retórica y performativa de la acción humana, especialmente la acción de la escritura académica (BAZERMAN, 2015; 2011; 2005; FIORIN, 2015; RAJAGOPALAN, 2014; 2008; 1998; HYLAND, 2011; 2000). Como resultado, esta investigación proporciona subsidios para una mejor comprensión de las visiones dominantes sobre escritura científica y sobre la necesidad de respetar la diversidad de culturas disciplinarias (HYLAND, 2011).

Palabras-clave: Redacción científica. Retórica. Performatividad. Culturas disciplinarias.

\section{Academic argumentation: an analysis of the rhetoric action of the Practical guide to scientific writing}

In this paper, we interpret some writing orientations of the Practical guide for scientific writing, which is, according to Volpato (2015), a manual that supports researchers in composition of academic papers fitting an international pattern. The goals of this text are to analyze: 1) rhetorical strategies mentioned by the Practical Guide that involve the production of knowledge on scientific writing and (2) positions on scientific writing (and, implied in this, on science in general) present in such guidelines. As a theoretical-methodological framework, we dialogue with studies that conceive language as social action and, in this sense, they emphasize the rhetorical and performative dimension of human action, mainly the academic writing action (BAZERMAN, 2015; 2011; 2005; FIORIN, 2015; RAJAGOPALAN, 2014; 2008; 1998; HYLAND, 2011; 2000). As a result, we offer subsidies for a better comprehension about dominant points of view concerning scientific writing and the needed respect to the diversity of disciplinary cultures (HYLAND, 2011).

Keywords: Scientific composition. Rhetoric. Performativity. Disciplinary cultures. 


\section{Introdução}

Neste estudo, realizamos uma leitura crítica sobre as principais orientações para escrita presentes no Guia prático para redação científica' (VOLPATO, 2015), um manual, segundo seu autor, destinado a auxiliar pesquisadores na escrita de artigos acadêmicos em um padrão internacional. De forma específica, nossos objetivos são: (1) analisar as estratégias retóricas na produção de conhecimento sobre escrita científica utilizadas em tais orientações; (2) analisar os posicionamentos sobre redação científica (e, implicado nisso, sobre ciência de maneira geral) presentes no manual analisado.

Para tanto, como referencial teórico, aproximamos perspectivas epistemológicas que concebem a linguagem como uma forma de ação que tem efeitos e consequências no mundo. Em outras palavras, estabelecemos diálogos entre pesquisadores e posições teóricas que, por um lado, salientam a heterogeneidade da escrita enquanto uma ação acadêmico-científica (BAZERMAN, 2011; HYLAND, 2011) e, por outro, ponderam sobre a ação retórica humana de maneira geral (RAJAGOPALAN, 1998; FIORIN, 2015) e científica, de maneira específica (RAJAGOPALAN, 1998; 2008; 2014; BAZERMAN, 2005; 2011).

Como já dito, a análise parte do manual Guia prático para redação científica (VOLPATO, 2015). A escolha justifica-se, primeiro, por ser uma obra prototípica a respeito da escrita científica, e, segundo, por ser um dos mais recentes livros lançados no Brasil com a finalidade de orientar a escrita de pesquisadores principiantes. Além disso, o discurso sobre mentalidade e escrita científica desse autor tem demonstrado ser bastante recepcionado por um público presente na internet. O seu canal do youtube, criado em dez de outubro de 2011, já teve 1.303.298 visualizações e está voltado para a produção de vídeos que discutem o mesmo assunto do livro.

Este estudo, portanto, tem como eixo central uma discussão crítica sobre o que se convencionou chamar de discurso científico e sua dimensão retórica (HYLAND, 2011). Segundo Bazerman (2011), quando se fala em retórica na escrita científica, busca-se acentuar a dimensão participativa de um pesquisador na Ágora Acadêmica a qual pertence, com a finalidade de influenciar seus pares em uma constante negociação sobre a produção, a reprodução e/ou a reformulação dos conhecimentos científicos de sua área. No entanto, o mesmo autor antecipa-se em dizer que essa metáfora não é totalmente feliz, visto que

\footnotetext{
10 presente trabalho é fruto das discussões que participamos durante a disciplina "Compreensão e produção do texto escrito", em 2017, no Programa de Pós-Graduação em Linguística da Universidade Federal do Ceará, ministrada pelo segundo autor. A referida disciplina versava sobre as relações entre leitura, produção textual e argumentação em gêneros acadêmicos, com foco nas características retóricas de diferentes áreas do conhecimento.
} 
[...] as situações, metas e ferramentas retóricas da ciência, das revistas científicas contemporâneas são bastante diferentes daquelas da Ágora de Atenas e, à medida que os meios simbólicos para a ciência se desenvolveram, eles foram distinguidos consistentemente das artes da oratória política (BAZERMAN, 2011, p. 64).

Com base nisso, nos filiamos a tal perspectiva com o objetivo de discutir alguns aspectos do Guia prático para redação científica que julgamos problematizáveis. Para tanto, o presente texto está dividido em três partes. Inicialmente, apresentamos algumas reflexões sobre as relações entre discurso acadêmico, cultura disciplinar e retórica científica. Depois, focalizamos pressupostos teóricos relativos à linguagem enquanto uma forma de ação, notadamente, em suas dimensões retórica e performativa e as consequências disso na produção de conhecimentos científicos. Em seguida, apresentamos e discutimos as orientações presentes no "Método Lógico" para redação científica de Volpato (2015). Nas considerações finais, comentamos os resultados da análise.

\section{Discurso acadêmico, cultura disciplinar e retórica científica}

Ponderações sobre as relações entre escrita e retórica em diferentes culturas disciplinares da esfera acadêmica têm sido foco de interesse de algumas pesquisas nos últimos anos (HYLAND, 2000, 2011; BAZERMAN, 2005, 2011, 2015). Variadas investigações discutem essas relações, por exemplo, as pesquisas vinculadas ao movimento "Escribir a través del currículum" (BAZERMAN et al., 2016). Nesta seção, apresentamos alguns pressupostos teóricos dessa recente tradição de estudo da linguagem, com a finalidade de fortalecer nossa compreensão sobre os dados selecionados para a análise.

Para melhor compreender as relações entre os conceitos supracitados, se faz necessário definir o que aqui estamos entendendo por discurso científico. É importante pontuar os distintos sentidos que o termo discurso pode assumir no abrangente campo de estudos da linguagem. A pluralidade de sentidos é discutida em Fairclough (2003). Para esse autor, três acepções são recorrentemente dadas à noção de discurso nas ciências humanas (entre elas, a Linguística), quais sejam: (1) discurso como prática de linguagem, um elemento de processos sociais; (2) discurso como o conjunto de representações ligadas a perspectivas particulares; (3) discurso como o uso da linguagem associada a um determinado domínio ou campo social (FAIRCLOUGH, 2003).

O primeiro refere-se à linguagem/semiose como prática social. $\mathrm{O}$ segundo relaciona-se com as diferentes maneiras de produzir sentidos e se posicionar no mundo social como, por exemplo, discurso patriarcal, discurso feminista, discurso racista, discurso xenofóbico, discurso neoliberal, entre tantos outros. O terceiro relaciona-se aos 
próprios campos sociais produtores de discursos, como, por exemplo, o discurso político, o discurso religioso, o discurso educacional, o discurso científico etc.

Ao observarmos as definições de discurso científico elaboradas por autores como Hyland (2011) e Bazerman (2011, 2015), percebemos que o conceito é pensado de maneira análoga à terceira definição de Fairclough (2003), ou seja, uma prática social específica a determinado campo ou esfera de atuação, ou, nas palavras do próprio Hyland (2011), práticas vinculadas a culturas disciplinares particulares.

De acordo com Hyland (2000, 2011), o discurso acadêmico materializa-se nas práticas científicas que, de alguma forma, estão relacionadas ao uso da modalidade escrita da língua, entre elas: o conjunto de gêneros (artigos, dissertações, teses, resenhas, resumos, livros especializados, conferências etc.) produzidos e lidos nas diferentes áreas do conhecimento científico. Com isso, esse pesquisador busca ressaltar que atuar e pertencer a uma disciplina é, fundamentalmente, participar de um conjunto de práticas de leitura e escrita consensuais a ela.

Após anos de estudo empírico sobre a escrita em diferentes áreas do conhecimento, Hyland (2000) encontrou regularidades que distinguem os textos nesses diferentes campos acadêmicos. Tais regularidades estão relacionadas a elementos como: objetivos a serem alcançados com a escrita; conceitos e categorias utilizados; formas de estruturar as seções; argumentos preferíveis; maneiras de relatar a metodologia; práticas de introduzir e concluir artigos, entre outros aspectos que caracterizam cada área do saber. Nas palavras do próprio autor, "[...] cada disciplina pode ser vista como uma tribo acadêmica com suas normas particulares, nomenclatura, corpos de conhecimento, conjuntos de convenções e modos de investigação que constituem uma cultura"2 (HYLAND, 2000, p. 8, tradução nossa). As diferentes disciplinas, nessa perspectiva, passam a ser compreendidas como culturas, isto é, são Culturas Disciplinares.

Nesse sentido, as teorizações sobre discurso acadêmico desenvolvidas por Hyland $(2000 ; 2011)$ associam práticas, costumes e concepções instituídas em dadas disciplinas acadêmicas com regularidades, convenções e hábitos culturalmente construídos, ou seja, as disciplinas acadêmicas funcionam, efetivamente, como culturas. Em outras palavras, a ideia de cultura disciplinar se configura enquanto um construto teórico que nos ajuda a entender a dinâmica da produção de conhecimento em diferentes domínios, campos ou espaços acadêmicos, reconhecidamente denominados de disciplinas.

\footnotetext{
2 No original: Each discipline might be seen as an academic tribe (Becher,1989) with its particular norms, nomenclature, bodies of knowledge, sets of conventions and modes of inquiry constituting a separate culture.
} 
De maneira semelhante, Bazerman et al. (2016) destacam a existência de relações bastante próximas entre, por um lado, ler e escrever em uma determinada disciplina (Linguística, Sociologia, História, Engenharia, Medicina etc.) e, por outro, pensar, categorizar, aprender e produzir conhecimento nesses mesmos campos disciplinares. De certa forma, nessa perspectiva, as disciplinas se caracterizam por serem espaços em que os pesquisadores, experientes e recém-chegados ao campo, negociam sentidos por meio da escrita. É, portanto, por meio da apropriação dos modos de escrever típicos daquele campo que aprendem como agir na cultura característica de sua disciplina acadêmica, ou seja, o pesquisador "[...] aprende o que precisa fazer e como deve agir para participar da atividade na comunidade, quais são os graus e extensões aceitáveis de variação e quais as sanções prováveis para eventuais violações" (BAZERMAN, 2011, p. 68).

Um tópico bastante enfatizado por Bazerman (2011) na escrita científica é, precisamente, os modos diferenciados de persuadir os pares nas distintas culturas acadêmicas. Segundo o autor, é imprescindível considerar os valores da comunidade em que o pesquisador está inserido, visto que "[...] quando você entra para adicionar seu enunciado, ele necessariamente precisa enfrentar a situação retórica estabelecida por aquela literatura, porque certamente será recebido e medido contra aquela construção coletiva" (BAZERMAN, 2011, p.67).

Isso está diretamente relacionado ao fato de que as disciplinas, entendidas como comunidades culturais, caracterizam-se por convenções (sobretudo, hábitos retóricos) que são pressupostos por seus membros integrantes. Em grande medida, essas convenções orientam elementos como conceitos epistemológicos, categorias analíticas e argumentos preferíveis. Desse modo, "[...] quanto mais se entende as pressuposições e as metas fundamentais da comunidade, melhor será sua capacidade de avaliar se os hábitos retóricos que você e seus colegas trazem para a tarefa são apropriados e efetivos" (BAZERMAN, 2011, p.65).

Para Hyland (2011), os pares de uma dada cultura disciplinar procuram "[...] mostrar familiaridade com as práticas persuasivas de suas disciplinas, codificando ideias, empregando regras e enquadrando argumentos de forma que seu público potencial considere mais convincente"3 (HYLAND, 2011, p. 195, tradução nossa). Dito de outro modo, a persuasão é algo que se constrói por convenções dos pares pertencentes a uma dada cultura acadêmica, uma vez que

[...] a persuasão em artigos acadêmicos, como em outras áreas da vida profissional, envolve o uso da língua para relacionar crenças independentes com experiências compartilhadas. Os escritores buscam o apoio, expressam a colegialidade,

\footnotetext{
3 No original: Must display familiarity with the persuasive practices of their disciplines, encoding ideas, employing warrants, and framing arguments in ways that their potential audience will find most convincing.
} 
resolvem as dificuldades e negociam o desacordo através de padrões de escolhas retóricas que conectam seus textos com suas culturas disciplinares ${ }^{4}$ (HYLAND, 2011, tradução nossa).

Nesse sentido, o autor ressalta que grupos de pesquisadores, habitualmente, seguem normas culturais disciplinares, de modo que compartilham objetos de pesquisa, modos de coletar/produzir dados, formas de evidenciar resultados etc., negociando sempre os conhecimentos de suas áreas através de argumentos e contra-argumentos preferíveis à sua própria coletividade disciplinar. Tendo feito essas considerações, o aspecto específico da dimensão retórica na produção de conhecimento científico será o foco da próxima seção.

\section{Textos como ações sociais situadas: retórica e performatividade na escrita científica}

Nesta seção, relacionamos perspectivas epistemológicas que tematizam os textos como formas de agir (retoricamente) no mundo social. De forma específica, articulamos teorizações que, por um lado, enfatizam a heterogeneidade do discurso acadêmico (BAZERMAN, 2011; HYLAND, 2011) e, por outro, salientam a necessidade de refletirmos sobre a dimensão retórica e performativa das ações discursivas humanas, de maneira geral (FIORIN, 2015; RAJAGOPALAN, 2014), e acadêmico-científicas, de maneira específica (RAJAGOPALAN, 1998; 2008; 2014; BAZERMAN, 2005; 2011).

Ao relacionar as perspectivas supracitadas, temos o propósito de criar um aparato conceitual apropriado para investigar as orientações de Volpato (2015) sobre redação acadêmica, com vistas a compreender as relações entre retórica e performatividade nos argumentos mobilizados pelo autor.

Fiorin (2015) afirma que a retórica é a arte da persuasão. A persuasão é alcançada via mobilização de argumentos que um enunciador utiliza com o propósito de levar os seus enunciatários a aceitarem uma tese e, com isso, conseguir convencê-los de algo. Segundo o linguista, a compreensão da retórica como objeto de estudo remonta a Aristóteles, filósofo que, em seus escritos, definiu três fatores essenciais à formulação de bons argumentos retóricos,

O primeiro trata do enunciador, de como ele concebe os argumentos, de como constrói seu éthos na enunciação; o segundo analisa o enunciatário, como ele recebe os argumentos em função do páthos; o terceiro estuda a mensagem, o lógos, como se expressam os argumentos (FIORIN, 2015, p. 19).

\footnotetext{
4 No original: Persuasion in academic articles, as in other areas of professional life, involves the use of language to relate independent beliefs to shared experience. Writers galvanise support, express collegiality, resolve difficulties, and negotiate disagreement through patterns of rhetorical choices which connect their texts with their disciplinary cultures.
} 
Seguindo a tradição aristotélica, Fiorin (2015, p. 17) diferencia dois tipos de raciocínios, a saber: lógicos e retóricos. Para ele, o raciocínio lógico situa-se no domínio do necessário, ou seja, "[...] é aquele cuja conclusão decorre necessariamente das premissas colocadas, ou seja, sendo verdadeiras as premissas, a conclusão não pode não ser válida". Um exemplo desse tipo de argumento é precisamente o clássico: Todo homem é mortal; João é homem; Logo, João é mortal.

O raciocínio retórico situa-se no domínio do preferível, ou seja, "a conclusão é possível, provável, plausível, mas não necessariamente verdadeira" (FIORIN, 2015, p. 18). Em outras palavras, os raciocínios lógicos "servem para demonstrar determinadas verdades", enquanto os retóricos "[...] destinam-se a persuadir alguém de que uma determinada tese deve ser aceita porque é mais justa, mais adequada, mais benéfica, mais convincente e assim por diante" (FIORIN, 2015, p. 18). Portanto, a lógica está preocupada com a verdade, independente de quaisquer considerações sobre valores morais, ao passo que a retórica está preocupada com o que é discutível em uma sociedade, envolvendo, portanto, crenças e juízos de valor.

A partir de um envolvimento teórico e prático com a perspectiva supracitada, no entanto, pondo em evidência em suas análises a modalidade escrita da língua, fato desconsiderado pela perspectiva clássica, Fiorin (2015) propõe que os diferentes estudos contemporâneos do discurso, para serem mais heurísticos em suas explicações, deveriam herdar a retórica, ou seja, levar em consideração, em seus procedimentos de análise, os séculos de reflexões já feitas sobre a argumentação.

Em um raciocínio similar ao de Fiorin (2015), Brandão (2001, p. 162) ressalta que enquanto para os lógicos a centralidade era precisamente a "problemática da linguagem enquanto representação", em que "se coloca a questão das condições do enunciado verdadeiro através da análise da proposição"; para os retóricos, deixava-se de lado a questão da verdade, com a finalidade de "apreender a linguagem como discurso produtor de efeitos, como poder de intervenção no real, como ação, atividade" (BRANDÃO, 2001, p. 163). Para essa autora, "a Pragmática é a Retórica dos antigos" (2001, p. 162). Ao dizer isso, ela salienta a proximidade entre as duas perspectivas teóricas, notadamente, no que diz respeito ao fato de que os antigos retóricos já teorizaram a respeito dos efeitos do discurso sobre o auditório. Nesse sentido, a retórica clássica teria fundado as bases das perspectivas linguísticas que temos hoje sobre a linguagem como uma forma de agir, em que se compreende a ação de um enunciador (falante e/ou escritor) como algo que tem efeitos práticos sobre seus enunciatários (ouvintes e/ou leitores).

Seguindo a mesma trilha, Rajagopalan (1998; 2008; 2014; 2016), filia-se abertamente a essa segunda perspectiva, que poderíamos chamar de pragmáticoretórica, argumentando que 
quando falamos qualquer coisa, os enunciados que são produzidos por nós não servem tão somente para retratar verbalmente o que se observa no mundo afora, isto é, uma realidade externa que, como se crê, existiria de forma independente e anterior a fala (RAJAGOPALAN, 2016, p. 85).

Dessa forma, por ser uma prática performativa (produtora de sentidos), "nossos atos de fala têm o propósito de efetivamente afetar, modificar, influenciar o que há no mundo e fazê-lo ao introduzir fatos novos a todo instante. E, ademais, ao fazer tudo isso, a nossa fala tem o poder de efetivamente intervir no mundo" (RAJAGOPALAN, 2016, p. 85).

Uma versão deste entendimento localiza-se, de forma bastante consolidada, na perspectiva teórica descortinada por Bazerman (2005; 2011; 2015). Apropriando-se das visões de linguagem da Teoria dos Atos de Fala criada por Austin (1990), Bazerman compreende os textos como "atos de fala" (sempre sociais) desenvolvidos em situações retóricas recorrentes. Bazerman (2005, p. 19), por exemplo, articula uma série de instrumentos conceituais e analíticos com a finalidade de pensar "como as pessoas criam novas realidades de significação, relações e conhecimento, fazendo uso de textos". Para o autor, conceitos como gêneros textuais, atos de fala, fatos sociais, sistemas de atividades, conjunto de gêneros, sistema de gêneros estão envoltos em uma compreensão de linguagem enquanto forma de agir no mundo social. No presente trabalho, interessa-nos, especificamente, as elaborações conceituais desse autor sobre atos de fala e fatos sociais.

De acordo com Bazerman (2015), os atos de fala e os fatos sociais estão profundamente relacionados, já que "os atos de fala modificam o mundo social criando novos fatos sociais, que modificam o que acreditamos, como interagimos socialmente e como agimos no mundo. Esses fatos sociais podem então modificar até mesmo nossa relação com o mundo material" (BAZERMAN, 2015, p. 89).

Dito de outro modo, os fatos sociais são constituídos por crenças e percepções que as pessoas acreditam que sejam verdadeiras. As pessoas orientam suas ações no mundo com base nos fatos sociais que acreditam. Os textos têm um papel importante na criação de fatos sociais para os seus leitores.

O alinhamento que fazemos das perspectivas de Rajagopalan (2016) e Bazerman (2005, 2015) deve-se ao fato deles operarem com uma compreensão de linguagem como ação e utilizarem essa perspectiva para explicar as características do discurso científico, especificamente, nas práticas de escrita.

Segundo Bazerman (2005), os conceitos de atos de fala e de fatos sociais são centrais para se compreender os processos de construção da(s) realidade(s), que são efeitos criados por textos concretos: 
Cada texto bem-sucedido cria para seus leitores um fato social. Os fatos sociais consistem em ações sociais significativas realizadas pela linguagem, ou atos de fala. Esses atos são realizados através de formas textuais padronizadas, típicas e, portanto, inteligíveis, ou gêneros, que estão relacionadas a outros textos e gêneros que ocorrem em circunstâncias relacionadas (BAZERMAN, 2005, p. 22).

As reflexões sobre escrita acadêmica dentro de um quadro conceitual da linguagem como ação (BAZERMAN, 2011; HYLAND, 2011; RAJAGOPALAN, 2014), nos dão fundamento para pontuar a dimensão pragmático-retórica, e, portanto, persuasiva da produção de conhecimento científico em diferentes campos do saber. Trata-se de como a escrita acadêmica constitui-se de formas de dizer/fazer de dadas comunidades científicas que historicamente estabelecem-se associadas aos gêneros produzidos por elas:

A epistemologia, a história e a teoria subjacentes de um campo não podem ser separadas de sua retórica. A ação retórica está preparada dentro de um mundo concebido e em busca de metas finais e imediatas. Quanto mais se entende as pressuposições e as metas fundamentais da comunidade, melhor será sua capacidade de avaliar se os hábitos retóricos que você e seus colegas trazem para a tarefa são apropriados e efetivos (BAZERMAN, 2011, p. 65).

Os autores supracitados colocam-se deliberadamente em oposição aos que pensam que o raciocínio lógico deve embasar todo e qualquer argumento científico, dado que "quem insiste em que toda argumentação é regida pela lógica, e que os limites da argumentação são impostos pelas leis da lógica está negando à retórica qualquer papel decisivo na condução de uma boa argumentação" (RAJAGOPALAN, 1998, p. 40).

De acordo com Rajagopalan (1998; 2008; 2014), o poder de convencimento do discurso científico advém daquilo que foi produzido e se convencionou como "verdade" aceita em dado momento histórico por pares de comunidades específicas - o que é compreendido por Bazerman (2005) como fato social. Em outras palavras, Rajagopalan (2008, p. 113) afirma que o discurso científico, como qualquer outro discurso, é também um ato performativo, dito de outro modo, este autor considera "todo conhecimento, inclusive o conhecimento científico, como construído socialmente pelos membros da comunidade em questão". Em vista disso, segundo Rajagopalan (2008), a verdade, portanto, não deveria ser pensada independente das estratégias retóricas mobilizadas por dadas comunidades para legitimação dos saberes, porquanto, um argumento que convence as pessoas em uma dada comunidade ou em dado momento histórico, pode deixar de fazê-lo em uma outra comunidade ou em um outro momento.

\section{A retórica constitutiva do "Método Lógico" para a redação científica}

Uma vez apresentada a articulação teórica em que nos baseamos, passamos, nesta seção, a analisar as orientações presentes no "Método Lógico", entendendo-as 
como conceitos e categorias que vão além de meras informações (neutras) sobre escrita acadêmica, posto que as concebemos como posicionamentos, retoricamente construídos, sobre como se produz conhecimento científico por meio da escrita. De forma específica, descrevemos o núcleo fundamental desta proposta metodológica, focalizando as principais estratégias argumentativas mobilizadas por Volpato (2015) na construção de suas teses a respeito da redação científica e, simultaneamente, interpretamos os efeitos de sentidos instituídos por meio dessas estratégias.

O que Volpato (2015, p. 20) tem denominado de "Método Lógico para a redação científica" é precisamente o resultado de sua experiência nas últimas décadas trabalhando com "Workshops para Redação Científica Internacional" em várias cidades brasileiras. O método, formalizado oficialmente em 2011, fundamenta-se, segundo seu proponente, em elementos lógicos e comunicativos, configurando-se, efetivamente, em orientações técnicas que objetivam a resolução de problemas com a escrita científica por parte de cientistas. Problemas esses relacionados às dúvidas que os cientistas possam ter a respeito de como relatar as pesquisas e, posteriormente, publicá-las em revistas internacionais. Desse modo, o autor acredita que "ao melhorarmos a formação científica e comunicacional dos cientistas, naturalmente melhoramos suas redações e publicações" (VOLPATO, 2015, p.17).

O método consiste em quarenta passos (entre dicas de como conceber a ciência e orientações sobre escrita científica) que integram sete grandes tópicos: "escolha e execute a pesquisa certa; encontre a sua história; entenda sua história; planeje; redija o texto; submeta o manuscrito; acompanhe o artigo" (VOLPATO, 2015, p. 27). Nas palavras do autor, trata-se de "uma sequência de passos que conduzem o processo de construção de ciência sólida e sua transformação num manuscrito de bom nível internacional, o que serve para construir os referenciais de uma vida científica ousada e competente" (VOLPATO, 2015, p. 20). Essa abordagem, portanto, tem o propósito de fornecer bases sólidas para que pesquisadores inexperientes aprendam a estruturar seus artigos em um suposto padrão lógico e comunicacional das revistas internacionais, em outras palavras,

[...] o objetivo é mostrar aos cientistas como usar um conjunto bem limitado de conhecimentos básicos necessários e suficientes para resolver quaisquer dúvidas durante a redação e publicação de um artigo científico. Assim, por esse método, corrigimos a escrita por meio do ensino das principais bases conceituais de ciência (lógica e comunicação) (VOLPATO, 2015, p. 26).

Os conceitos e as categorias teóricas manejadas por Volpato (2015) em suas reflexões sobre escrita científica são fortemente vinculados ao que ele entende por ciência, escrita e argumentação (lógica). A obra que estamos analisando focaliza sua discussão no gênero artigo acadêmico (embora não utilize em nenhum momento a noção de gênero). $\mathrm{O}$ artigo acadêmico resulta de uma dada experiência científica que 
se remete a uma pesquisa feita e está sendo relatada por escrito. Nessa perspectiva, o texto científico caracteriza-se por sua arquitetura lógica (premissas e conclusões) e sua capacidade de comunicação com os pares acadêmicos. Nas palavras do próprio autor,

[...] o importante disso para a redação científica é que um bom argumento deve ter premissas suficientes para sustentar as conclusões e não deve conter premissas fracas e nem premissas em excesso. Conhecendo as premissas, elaboramos as conclusões (VOLPATO, 2015, p. 48).

Além de prezar pela "lógica" e pela "boa comunicação", um elemento que se apresenta como fundamental nesse método é a postulação de um sistema científico internacional para redação acadêmica. Dito de outro modo, os conhecimentos necessários àqueles que produzem artigos científicos são compreendidos como, fundamentalmente, vinculados a um sistema que rege princípios essenciais a todas as áreas pertencentes ao domínio científico. Assim, para esse autor, há princípios gerais na redação de artigos em todas as áreas que merecem o nome de científicas, ou, como o ele mesmo reitera "[...] falo em ciência e não em especialidade científica. Falo do conhecimento sobre o sistema científico que permeia todas as especialidades de todas as áreas" (VOLPATO, 2015, p. 26). Conhecer o referido sistema ajudaria os pesquisadores a evitar o autor chama de "vícios de áreas", uma vez que

[...] o perfil das estruturas de artigo defendidas neste livro é coerente com o que encontramos em revistas internacionais, principalmente naquelas da supraespecialidade. No caso das revistas internacionais tradicionais de uma especialidade, a situação pode ser mais complicada. Nelas há vícios de áreas [...] os quais atrapalham pensar o texto apenas a partir das bases sólidas da ciência e do meio comunicacional (VOLPATO, 2015, p. 19).

Para demonstrar como estrutura-se o texto científico, o "Método Lógico" propõe uma dada composição que, segundo Volpato (2015, p. 48), é formada por duas grandes seções:

\section{(1) Introdução}

Premissa: conjunto de informações necessárias para apresentar e justificar a problemática na qual se insere 0 artigo e as informações que fundamentam 0 objetivo escolhido.

Conclusão: objetivo do estudo.

(2) Métodos, resultados e discussões

Premissa: conjunto informações que nos métodos valide os resultados; todos os resultados e informações da literatura que validem as conclusões.

Conclusões: conclusões dos trabalhos que são defendidas pelos autores. 
A estrutura do artigo científico, portanto, assim como um argumento lógico, é composta por premissas e conclusões. Nesse sentido, a primeira seção - introdução é compreendida como o espaço onde escritores devem apresentar informações que funcionem como premissas para sustentar determinadas conclusões, essas entendidas como os objetivos do estudo. Ou seja, por meio da reunião de determinadas informações (premissas da introdução), que podem advir daquilo que o pesquisador "observou/constatou concretamente (aceita que existe, que faz parte do mundo natural)" (VOLPATO, 2015, p. 50), chega-se a fundamentar um objetivo (conclusão da introdução) para a pesquisa. O mesmo raciocínio empreende-se na segunda seção (métodos, resultados e discussões) em que a inclusão ou não de informações também está a serviço de sustentar dadas conclusões.

Nesse ponto de vista, produzir ciência por escrito é tão somente demonstrar, de forma estruturada, via lógica (ideias não contraditórias) uma dada verdade que emerge das evidências naturais. Todo esse processo é encarado como argumentações que estão a serviço de, e possibilitam, sustentar determinadas conclusões.

Por acreditarmos que as postulações de Volpato (2015) são simultaneamente atos retóricos e performativos que produzem dados sentidos sobre como deve ser a redação acadêmica de excelência, nossa análise visa ressaltar como o autor em questão age com a língua (em suas orientações) para produzir conhecimento sobre escrita científica, notadamente, como iremos mostrar a seguir, a partir de três estratégias principais, detalhadas em Fiorin (2015), a saber: (1) argumentação por definição; (2) argumentação por recurso a determinados valores e (3) argumentação por implícitos.

Em nossa interpretação, as definições apresentadas por Volpato (2015) para caracterizar como funciona a escrita na ciência internacional vinculam-se a seus investimentos retóricos. Segundo Fiorin (2015, p. 118), as definições estão sempre alicerçadas a projetos persuasivos específicos, isto é, diferente de como muitos pensam

[...] não há uma maneira unívoca de definir um objeto. Ao contrário, o modo de definir depende das finalidades argumentativas. As definições impõem um determinado sentido, estão orientadas para convencer o interlocutor de que um dado significado é aquele que deve ser levado em conta. Por isso, elas podem ser conflitantes.

Tendo isso em mente, percebemos, nas definições apresentadas por Volpato (2015), determinados pontos de vista que estão vinculados aos interesses desse autor em construir uma linguagem lógica e padronizada que abarque todas as áreas do saber científico.

Volpato (2015, p. 28) nos apresenta duas definições de ciência, quais sejam: "a) a forma como construímos o conhecimento; b) o conjunto de conhecimentos produzidos". Logo em seguida, diz que "a ciência visa [...] compreender, explicar, dar 
sentido às coisas que vemos; [...] entender os fenômenos naturais, que são todos aqueles que sabemos existir no universo" (VOLPATO, 2015, p. 28). Como arremate final, postula que o conhecimento científico deve "ser sustentado por base empírica" e que "essa base empírica deve ser universal, obtida ou percebida, no mínimo, por quaisquer cientistas da área” (VOLPATO, 2015, p. 29).

Ademais, quando o autor postula que "a ciência é lógica" (VOLPATO, 2015, p. 24) e detalha a composição do artigo científico em premissas e conclusões, está, mais do que simplesmente descrevendo seu modo de fazer, argumentando via definições. Tais definições estão perpassadas por teses implícitas a respeito do que pode ser chamado de ciência e de como produzi-la com a escrita. Isso está bem resumido no trecho em que o autor ressalta que os recursos da lógica "têm profundas implicações para a estruturação de um artigo científico, bem como para a forma redacional. Elas são os direcionamentos em quaisquer estudos da ciência empírica" (VOLPATO, 2015, p. 40).

A julgar por esses raciocínios oferecidos por Volpato (2015), todo o percurso de montagem de um artigo científico seria regido pela lógica. Em outras palavras, o descobrimento da "verdade científica" e posterior relato só seria possível mediante o rigor balanceado de premissas e conclusões. Em nenhum momento, sinaliza-se, por exemplo, para eventuais diferenças composicionais do gênero artigo científico produzido em diferentes áreas do conhecimento.

Em outra faceta das definições de Volpato (2015), observamos que, nos raciocínios por ele elaborados, recorre-se a terminologias, a convenções, a modos de pensar típicos das ciências naturais. Isso é evidenciado quando, ao discorrer sobre noções como "tamanho da amostra", "replicagem da pesquisa" e "controle de variável", o autor orienta que o pesquisador que almeja desenvolver uma pesquisa de qualidade "atente para o tamanho amostral" e "veja o número de réplicas que usa para avaliar variáveis que podem ser de seu interesse" (VOLPATO, 2015, p.74).

Em outro ponto das orientações, fala da importância de organizar o texto com base na construção de variáveis e, com isso, ressalta: "considero variável qualquer tipo de elemento do mundo natural que possamos estudar na ciência empírica" (VOLPATO, 2015, p. 34). Com essa maneira de conceber a questão, receberia o selo de ciência somente a pesquisa que visa "construir explanações gerais sobre o mundo natural. Em palavras antigas, diríamos que visa propor teorias científicas" (VOLPATO, 2015, p. 30).

O léxico utilizado nas definições de Volpato (2015) revela que o seu interesse principal de ajudar a solucionar problemas de escrita dos cientistas brasileiros, possibilitando-Ihes atingir revistas internacionais com alto fator de impacto, se circunscreve à investigação do "mundo natural". Outro exemplo desse raciocínio aparece na passagem em que são apresentadas as revistas científicas por ele consideradas fundamentais: "as revistas do nível supraespecialidade são bem 
conhecidas: a Nature e a Science" (VOLPATO, 2015, p. 18). Uma rápida pesquisa revela que são ambas revistas das ciências naturais. Esse raciocínio é ainda mais explicitado quando o autor define a redação científica por meio de uma metáfora específica, a saber: "imagine que o texto científico seja um conjunto de informações extremamente conectadas entre si. Imagine uma grande molécula, com seus átomos conectados entre si. Se mexer num dos átomos, mexerá no restante. Assim é o texto científico" (VOLPATO, 2015, p. 95).

Nos trechos acima, percebemos a utilização dos termos "ciência" e "natural", correlacionados, como se um não existisse sem o outro, para descrever as características do conhecimento científico. Diante disso, nos questionamos: o método lógico não teria o objetivo de ensinar todas as áreas do conhecimento a escrever seguindo um padrão internacional? Por que se restringir à investigação sobre o "mundo natural"? Em nossa compreensão, os trechos supracitados, longe do ideal universalizante almejado, exemplificam o que, de maneira sistemática, as pesquisas desenvolvidas há um bom tempo pelos estudiosos da retórica acadêmica vêm demonstrando (BAZERMAN, 2011; HYLAND, 2011), quer dizer, cada área possui um modo particular de produzir conhecimento com a escrita.

A rigor, as definições de Volpato (2015) são performativas, ou seja, produzem a ideia de que se faz necessário estabelecer padrões fixos para a escrita no mundo acadêmico (diga-se de passagem, padrões típicos das ciências naturais a serem emulados pelas demais áreas). Ou seja, o conceito chave desse raciocínio é "adequação", isto é, as pesquisas específicas e as áreas do conhecimento que aspiram ao posto de ciência devem adequar-se ao "Método Lógico". Em outras palavras, para serem bem-sucedidos em suas carreiras acadêmicas, os recém pesquisadores são levados a acreditar que a homogeneidade é essencial ao fazer científico.

Nas orientações de Volpato (2015), a lógica está diretamente vinculada à clareza na linguagem. Segundo esse autor, para escrever um texto de excelência, é necessário cuidado com a lógica das ideias, de modo que as informações estejam claras. Ou seja, "ideias claras num texto científico significa saber qual a hierarquia entre as conclusões elaboradas e quais informações (resultados do próprio trabalho e da literatura) sustentam cada conclusão" (VOLPATO, 2015, p. 51). De certa forma, ao defender em seu "Método Lógico" a clareza como requisito essencial da comunicação, esse autor está, de maneira consciente ou não, filiando-se a uma concepção de linguagem (e de realidade) concebida como algo transparente que pode (desvinculada de intenções e interesses dos enunciadores) retratar o mundo de maneira fidedigna (RAJAGOPALAN, 2008; 2016).

Ora, em nossa percepção, essa é mais uma forma de argumentar empregada pelo autor. Uma estratégia de "recurso a determinados valores" que, segundo Fiorin (2015), 
consiste em apresentar dados raciocínios tratando-os como sendo da ordem da evidência e da normalidade, isto é, aquilo que deveria ser aceito por todos que são "normais" e "ajuizados". Ou seja, recorre-se ao lugar comum da transparência da linguagem associada à transparência de caráter do enunciador e, por consequente, à verdade por ele proferida. Nesse raciocínio, a linguagem é lógica, e a lógica é uma parte da matemática. E, portanto, pressupõe-se que matematizar a escrita científica é algo que ninguém de bom senso deveria se opor.

A mesma estratégia é utilizada quando o autor apresenta como óbvio, evidente e incontestável que pesquisadores principiantes (todos eles) escrevem mal e, portanto, devem recorrer ao seu Método Lógico, que seria um conjunto de conhecimentos "básicos", "necessários" e "suficientes" para escrita científica em qualquer área, visto que a lógica é algo que constitui o próprio pensamento humano (VOLPATO, 2015, p. 40), ou seja, faz parte de sua natureza.

Com tais argumentos, Volpato (2015) advoga a tese de que a lógica para escrita científica é em si mesmo um valor (natural) a ser defendido por todos, ou seja, o normal a ser feito. Em resumo, o autor coloca-se como alguém embasado na razão transparente (e lógica) e na normalidade, enquanto, implicitamente, classifica os argumentos opostos como contrários à própria natureza. De acordo com Fiorin (2015, p. 201), é preciso desconfiar desse tipo de argumento. Visto que, invariavelmente, ele está perpassado por posições conservadoras, "detrás do normal, há sempre uma norma, que não é universalmente válida, mas socialmente construída com valores de um dado tempo, num determinado espaço".

Uma terceira estratégia utilizada é, precisamente, o que Fiorin (2015, p. 206) chama de argumentação por implícitos. Segundo este autor, a estratégia assemelha-se bastante ao recurso aos valores, visto que, quando enunciamos, algumas informações estão explícitas, enquanto outras ficam implícitas. Sendo que o "implícito é o que se diz sem dizer, é aquilo que se apresenta como evidente por si mesmo" (FIORIN, 2015, p. 206). Ou seja, aquilo que é tratado como pressuposto e subentendido. De acordo com Bazerman (2011), grande parte do conhecimento a respeito das práticas de leitura, escrita e oralidade científicas resultam de regras culturais não ditas. Essas práticas constituem efetivamente a cultura de cada disciplina e isso tem impactos em suas práticas letradas. Volpato (2015) parece ter consciência dessa máxima.

Nos atos de fala que constituem o "Método Lógico", encontramos sentidos explícitos e sentidos implícitos. Um implícito essencial à argumentação de Volpato (2015) é, precisamente, a negação do raciocínio retórico. Ironicamente, a retórica é negada e simultaneamente praticada por esse autor. Como constatamos, os atos de fala de Volpato (2015) estão fundamentados por uma cadeia de argumentos que dissimulam via o manto sagrado da ciência (RAJAGOPALAN, 2014) seu interesse de 
fazer com que seus interlocutores adiram a suas teses, sejam persuadidos, convencidos de que ele Ihes oferece a "Verdade Lógica". Dito de outro modo, Volpato (2015) confunde aquilo que para ele, ou para sua comunidade, é um fato social (uma verdade) com "a Verdade" universal aceita por todas as áreas do saber.

Em última instância, seus atos de fala não descrevem realidades, mas sim instituem aquilo que passa como verdade ou fato social. Como postula Rajagopalan (2008, p. 7), "os fatos da ciência são resultantes de atos performativos praticados pelos cientistas". Assim, "o erro está em pensar que estejamos engajados em atos proposicionais, que são regidos pela lógica formal, quando na verdade estamos engajados - o tempo todo - em atos ilocucionários, que são retóricos". Isso fica perceptível quanto Volpato (2015) constrói um conjunto de raciocínios retóricos (com crenças e valores envolvidos) para defender seu ponto de vista, ou seja, a tese de que há somente um modo legítimo de fazer ciência e, portanto, a rigor, aqueles que não se enquadram ou agem/pensam diferente não estariam fazendo ciência de verdade.

Em resumo, os fatos sociais instituídos por Volpato (2015) provavelmente terão mais sucesso em persuadir e convencer os seus pares, ou seja, sua comunidade acadêmica. Posto que "[...] aquilo que soa para alguém como uma boa explicação, uma explicação convincente, pode parecer a uma outra pessoa como qualquer coisa menos uma explicação" (RAJAGOPALAN, 2014, p. 10).

\section{Considerações finais}

Nesta reflexão, constatamos que Volpato (2015) apresenta orientações para a escrita científica um tanto generalistas, pois não leva em consideração o fato de que áreas diferentes escrevem e argumentam de maneira distinta e, portanto, produzem conhecimento científico de acordo com seus hábitos e convenções disciplinares. Numa tentativa generalizada de conceituar o artigo acadêmico, Volpato (2015) lança mão de nomenclaturas e raciocínios típicos das ciências naturais. É importante ressaltar que sua principal formação acadêmica é justamente em Ciências Biológicas, um dos campos das ciências naturais. Isso atesta justamente o que, há tempos, estudiosos de gêneros acadêmicos, escrita e discurso científico defendem sobre os modos particulares de produzir o conhecimento (BAZERMAN, 2005; 2011; 2015; HYLAND, 2000; 2011).

Ao recomendar seu Método Lógico para a redação científica (composto por uma estrutura composicional formada por sequências lógicas, ou seja, premissas e conclusões) como uma receita matemática a ser seguida por todas as áreas do conhecimento científico, o autor demonstra seu posicionamento com relação à suposta superioridade das ditas ciências exatas e naturais. Ou seja, seus escritos são orientados por um olhar valorativo específico que hierarquiza áreas do conhecimento científico, a 
ponto de naturalizar a ideia de que todas as áreas deveriam seguir o modelo científico da cultura disciplinar que ele pertence. Em síntese, percebemos que é por meio de estratégias retóricas que Volpato (2015) busca a adesão de seus leitores, sejam eles de qualquer comunidade científica.

Postulamos que este estudo pode auxiliar em uma maior reflexão crítica a respeito de algumas ideias sobre redação científica (por exemplo, ideias sobre inferioridade científica de algumas áreas por conta de seus modos de agir por escrito) que, eventualmente, podem tornar-se hegemônicas e, por um processo performativo, passarem a ser aceitas como fatos sociais. Esperamos, por fim, contribuir, pedagogicamente, com uma visão mais heterogênea sobre a escrita acadêmica, pois, como mostram Araújo, Dieb e Costa (2017, p. 730),

[...] o ensino dos gêneros consagrados na academia implica uma tarefa extremamente importante e igualmente complexa, exigindo, daqueles que se propõem a enfrentá-la, tanto habilidades no domínio dessa esfera discursiva quanto capacidade didática para apresentar aos alunos o raciocínio que permeia esse tipo de discurso.

Desse modo, é desejável o cultivo de uma prática de ensino mais apropriada para lidar com a diversidade e, em vista disso, que considere a alteridade, característica das distintas culturas disciplinares.

\section{Referências}

ARAÚJO, Júlio.; DIEB, Messias; COSTA, Sayonara. O QNP e as dificuldades de construção do objeto de pesquisa: uma experiência de aprendizagem mediada sobre o gênero projeto de pesquisa. DELTA, São Paulo, v. 33, n.3, p. 729-757. 2017. Disponível em https://www.scielo.br/pdf/delta/v33n3/1678-460X-delta-33-03-00729.pdf Acesso em: 16 set. 2020.

AUSTIN, John. How to do things with words. Cambridge: Harvard University Press, 1990.

BAZERMAN, Charles. Atos de fala, gêneros textuais e sistemas de atividades: como textos organizam atividades e pessoas. Tradução: Judith Hoffnagel. In: BAZERMAN, Charles. Gêneros textuais, tipificação e interação. São Paulo, Editora Cortez, 2005. p. 19-46.

BAZERMAN, Charles. Escrevendo bem, cientificamente e retoricamente: consequências práticas para escritores da ciência e seus professores. Tradução: Judith Hoffnagel. In: BAZERMAN, Charles. Gênero, agência e escrita. São Paulo: Cortez, 2011. p. 59-78.

BAZERMAN, Charles. Retórica da ação letrada. Tradução: Adail Sobral, Angela Dionisio, Judith Hoffnagel e Pietra Acunha. São Paulo: Parábola Editorial, 2015.

BAZERMAN, Charles et al. Escribir a través del currículum: un guía de referencia. Edición: Federico Navarro. Córdoba: Editora de la Universidad Nacional de Córdoba, 2016. 
BRANDÃO, Helena. Pragmática linguística: delimitações e objetivos. In: MOSCA, Lineide (org.). Retóricas de ontem e hoje. São Paulo: Humanitas, 2001. p. 161-182.

FAIRCLOUGH, Norman. Analysing discourse: textual analysis for social research. Londres: Routledge, 2003.

FIORIN, Luiz. Argumentação. São Paulo: Contexto, 2015.

HYLAND, Ken. Disciplinary discourse: social interactions in academic writing. Singapura: Pearson Education Limited, 2000.

HYLAND, Ken. Academic discourse: English in a global context. London: Continuum, 2011.

RAJAGOPALAN, Kanavillil. A dimensão crítica da teoria dos atos de fala. In: FERREIRA, Ruberval; RAJAGOPALAN, Kanavillil (orgs.). Um mapa da crítica nos estudos da linguagem e do discurso. Campinas: Pontes Editores, 2016. p. 85-94.

RAJAGOPALAN, Kanavillil. O discurso científico, seus desdobramentos e seus embustes. In: GONÇALVES, Adair; GÓIS, Marcos (orgs). Ciências da linguagem: o fazer científico. v. 2. Campinas: Mercado de Letras, 2014. p. 7-24.

RAJAGOPALAN, Kanavillil. Argumentação e discurso científico numa perspectiva pragmática. Revista do GEL, Araraquara, v. 37, p. 113-119, 2008. Disponível em: http://www.novomilenio.inf.br/nmlogs/log/2008000c.pdf. Acesso em: 12 out. 2021.

RAJAGOPALAN, Kanavillil. A verdade na/da argumentação. Cadernos de Estudos Linguísticos, Campinas, v. 35, p. 39-48, 1998. Disponível em: https://periodicos.sbu.unicamp.br/ojs/index.php/cel/article/view/8637127. Acesso em 12 out. 2021.

VOLPATO, Gilson. Guia prático para redação científica. Botucatu: Best Writing, 2015. 